\title{
Application of Building-scale Calorimetry
}

\author{
JEFFERY S. NEWMAN, CHRISTOPHER WIECZOREK, and JOAN M.A. TROUP \\ Protection Research \\ FM Global \\ 1151 Boston-Providence Turnpike \\ Norwood, Massachusetts 02062 USA
}

\begin{abstract}
The Large Burn Laboratory, located at the FM Global Research Campus, is the first facility in which calorimetry techniques have been become a standard means of evaluating both sprinklered and non-sprinklered fire tests. The geometry and dimensions of the new facility result in signal distortions which are not typically seen with smaller scale calorimeters. Correction techniques to the measured signals have been developed to account for both accumulation and dilution of the combustion products between the source and the measurement locations. The theory and calculations required to calculate the chemical heat release rates for building-scale fire tests are presented and discussed. The correction schemes are applied to two fire tests, a free-burn spray fire and a sprinklered "standard plastic" rack storage fire. The calculated chemical heat release rates are then compared to theoretical calculations and observed events.
\end{abstract}

KEYWORDS: calorimetry, chemical heat release rate, species dilution, time constant

\section{NOMENCLATURE LISTING}

$\begin{array}{lll}C O & \text { carbon monoxide } & - \\ C O_{2} & \text { carbon dioxide } & - \\ \Delta h_{c, i} & \text { net heat of complete combustion for species i } & \mathrm{kJ} / \mathrm{kg} \\ \dot{Q}_{c h e m} & \text { chemical heat release rate } & \mathrm{MW} \\ M W_{i} & \text { molecular weight of species i } & \mathrm{kg} / \mathrm{mole} \\ X_{i} & \text { mole fraction of species i } & - \\ \dot{m}_{i} & \text { mass flow rate of species i } & \mathrm{kg} / \mathrm{s} \\ \dot{m}_{\text {flow }} & \text { total mass flow rate } & \mathrm{kg} / \mathrm{s} \\ P & \text { duct pressure } & \mathrm{Pa} \\ P_{o} & \text { ambient pressure } & \mathrm{Pa} \\ T & \text { gas temperature } & \mathrm{K} \\ \tau & \text { time constant } & \mathrm{sec} \\ t & \text { time } & \mathrm{sec} \\ X(t)_{i, \text { measured }} & \text { measured signal } & \\ X(t)_{i, \text { corrected }} & \text { corrected signal } & \\ V & \text { volume above ceiling } & \\ \dot{V} & \text { volumetric flow rate of gases } & \mathrm{m}^{3} \\ y_{w} & \text { humidity ratio } & \mathrm{m}^{3} / \mathrm{s} \\ & & \mathrm{kg} / \mathrm{kg}\end{array}$




\section{INTRODUCTION}

Despite advances in fire modeling, especially in the area of flow visualization, large-scale fire testing remains the definitive method for assessing fire hazards and, in particular, the efficacy of fire protection methodologies. The advent of large-scale heat release rate calorimeters into the MW range has provided an important tool in the characterization of realistic-scale material configurations [1].

Recently, the Large Burn Laboratory, located at the FM Global Research Campus, became fully operational. This unique $10,000 \mathrm{~m}^{2}$ facility is the world's largest laboratory dedicated to fire protection research. Through an innovative design, this laboratory is able to simulate, under carefully controlled ventilation conditions, a wide range of realistic fire scenarios. For the first time, heat release rates can be accurately quantified during sprinklered fire tests. Simultaneous determinations of global fire gas characteristics have been coupled with novel techniques for determining local fire field "true" gas temperatures, moisture contents and velocities.

The facility design and instrumentation allow chemical heat release rates to be determined during both sprinklered and non-sprinklered fire tests. This paper will discuss the calculation techniques along with presenting various test cases to illustrate the application of calorimetry on a building scale.

\section{FACILITY SPECIFICATIONS}

Illustrations of the Large Burn Laboratory are shown in Fig. 1. On the right is a top view of the entire Large Burn Laboratory, including the movable and fixed ceilings and the 20 MW Calorimeter. On the left is the air emission control system (AECS) exhaust ducting for the movable ceiling and the $20 \mathrm{MW}$ Calorimeter. Ducting identical to that of the movable ceiling is also located above the fixed ceiling. The ceiling ducting consists of four extraction points which merge into a single duct with a cross sectional area of $6.13 \mathrm{~m}^{2}$. Gas concentration, velocity, temperature, and moisture measurements are made downstream of the manifold. Beyond the measurement location, the exhaust duct connects to a wet electrostatic precipitator (WESP), not shown, prior to the gases venting to the ambient.

Figure 2 is an artist's rendition of a palletized storage fire under the movable ceiling highlighting the relative positions of the viewing gallery and the 20 MW Calorimeter.

The movable ceiling is adjustable for heights ranging from $3.05 \mathrm{~m}(10 \mathrm{ft})$ to $18.3 \mathrm{~m}$ $(60 \mathrm{ft})$. Therefore, the volume of space above the ceiling, in which combustion products accumulate and mix, ranges from $3,354 \mathrm{~m}^{3}$ to $27,310 \mathrm{~m}^{3}$ and impacts transport and mixing times. 

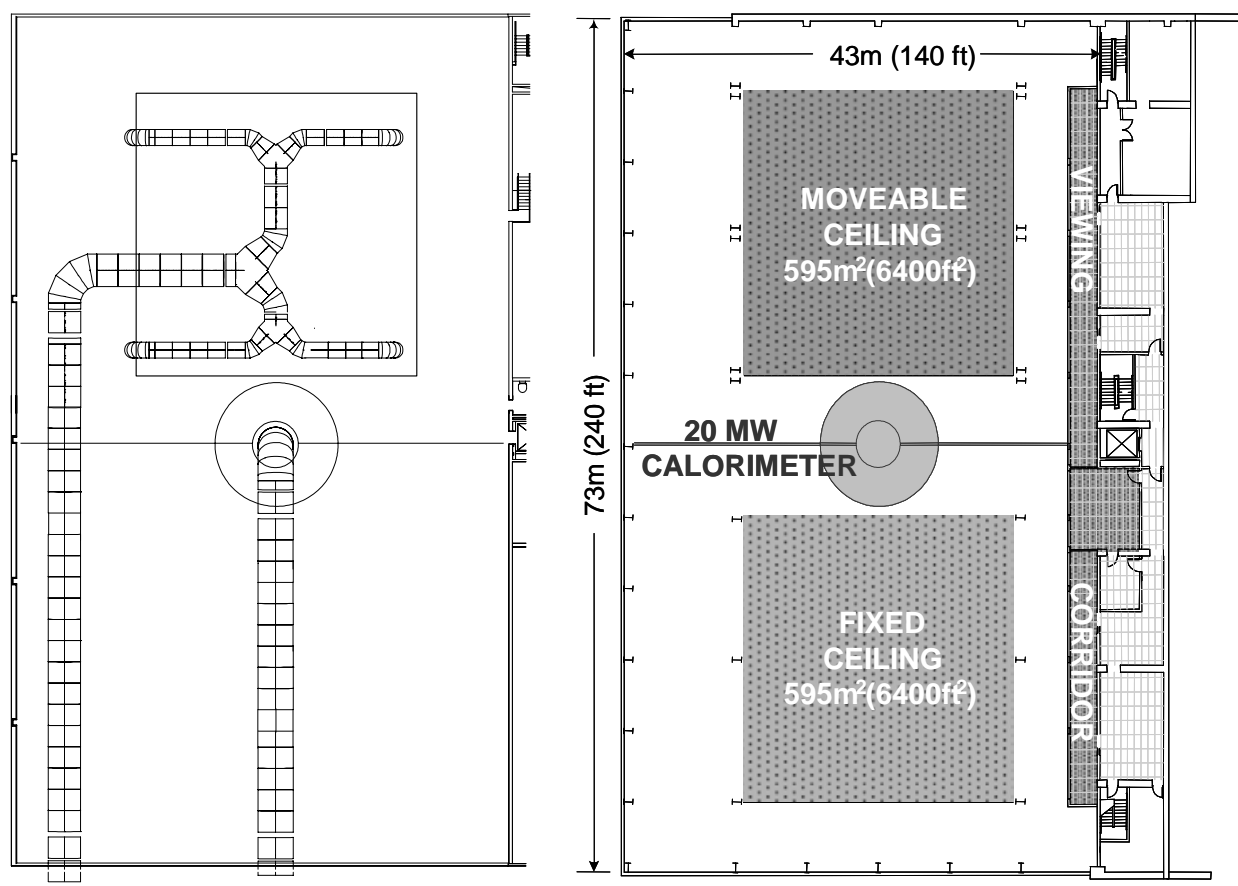

Fig. 1. Illustrations of AECS exhaust ducting and Large Burn Laboratory test sites.

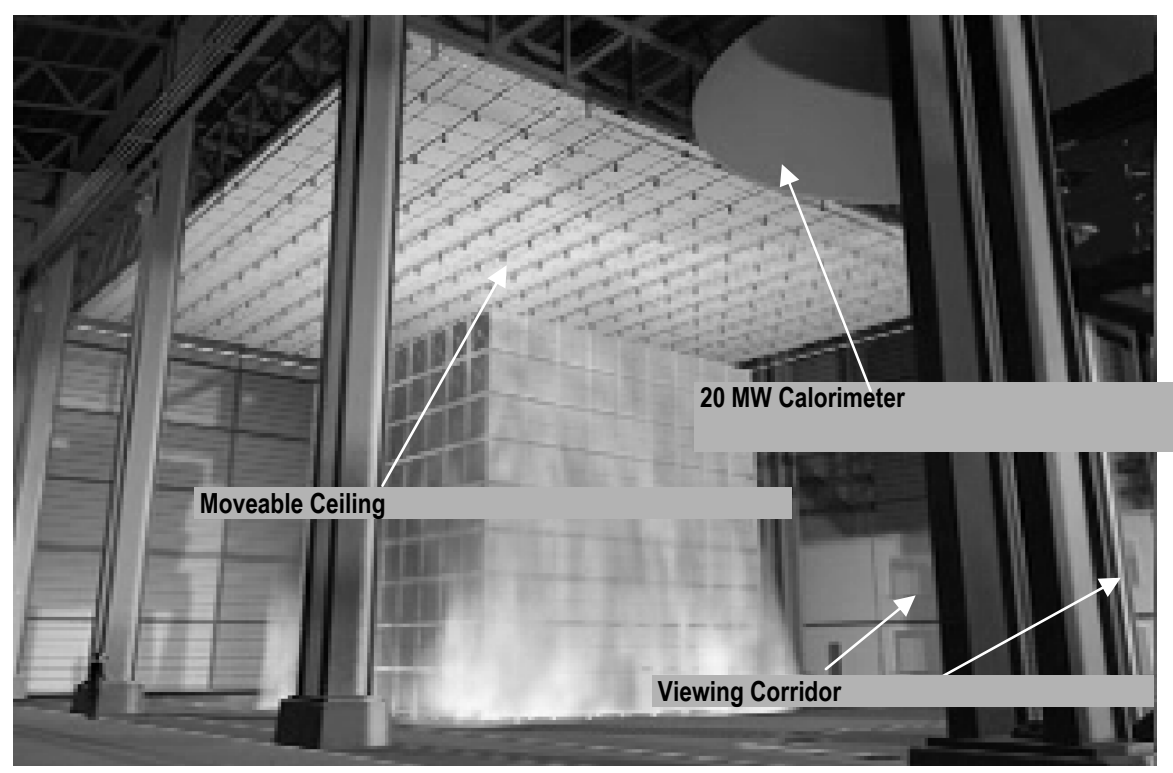

Fig. 2. Artist's rendition of a palletized storage fire. 
Figure 3 shows the 20 MW Calorimeter located between the fixed and movable ceilings. At the base, the $10.7 \mathrm{~m}$ diameter cone is $11.3 \mathrm{~m}$ above the laboratory floor. The cone is $3.8 \mathrm{~m}$ high and connects into $3.05 \mathrm{~m}$ diameter ducting. All measurements are made in the duct downstream of the cone entrance.

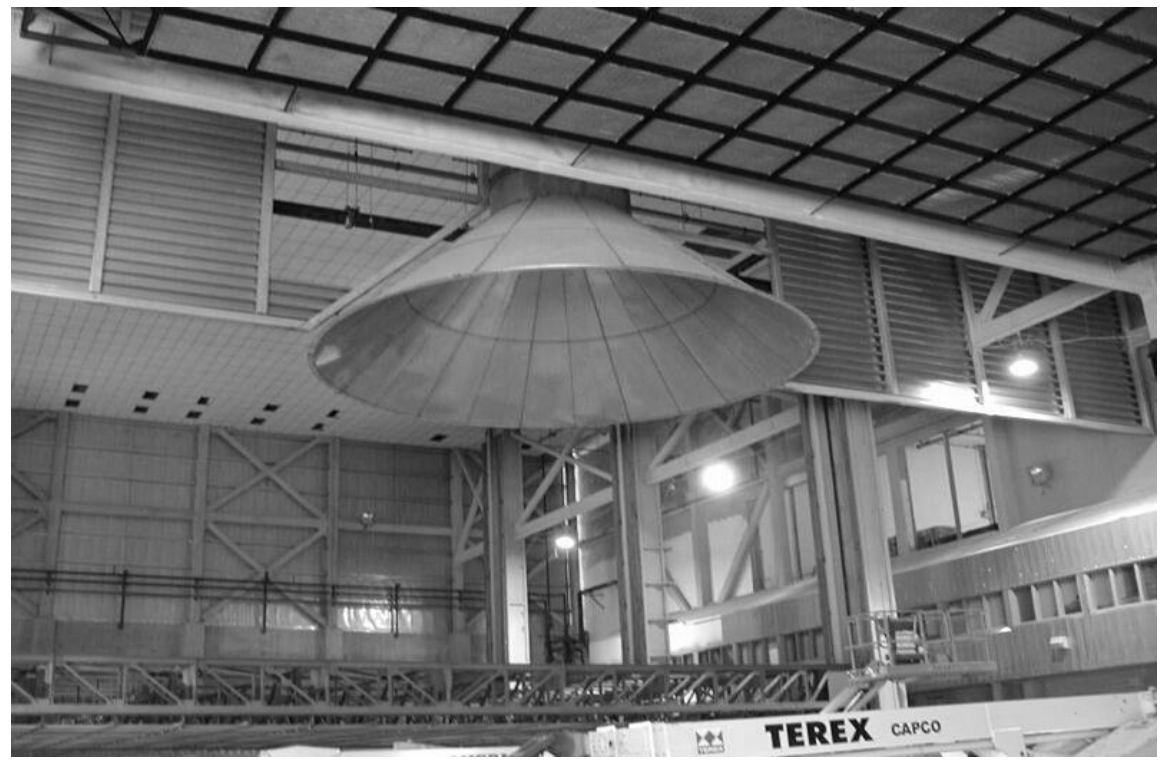

Fig. 3. 20 MW Calorimeter.

\section{THEORY}

Measurement of the exhaust gases allows chemical heat release rates to be calculated by either oxygen depletion or carbon dioxide/carbon monoxide generation techniques. All calculations and discussions within this paper will focus on the later. Chemical heat release rates based on carbon dioxide and carbon monoxide generation are calculated by Eq. 1, based on methodology developed by Tewarson [2].

$$
\dot{Q}_{\text {chem }}=\Delta h_{c, \mathrm{CO}_{2}} \dot{\mathrm{m}}_{\mathrm{CO}_{2}}+\Delta h_{c, \mathrm{CO}} \dot{m}_{\mathrm{CO}}
$$

The mass flow rate of each species generated, $\dot{m}_{i}$, is determined by

$\dot{m}_{i}=\dot{m}_{\text {flow }}\left(\frac{M W_{i}}{M W_{\text {mixture }}}\right) X_{i, \text { corrected }}$

Two variables within Eq. 2 need to be discussed in detail, $\dot{m}_{\text {flow }}$ and $X_{i, \text { corrected }}$. For accurate calorimetry measurements during sprinklered fire tests, mass flow contributions from moisture due to both combustion and sprinkler water application should ideally be considered. Moisture measurements within the exhaust duct allow the mass flow rate of exhaust gases to be calculated on a dry basis: 
$\dot{m}_{\text {flow }}=26.63 C A \sqrt{\frac{P}{P_{o}}} \sqrt{\frac{\Delta P}{T}}\left[\left(\frac{1+y_{w}}{1+y_{w} / 0.611}\right)^{1 / 2} /\left(1+y_{w}\right)\right]$

"This reduction calculates the mass flow of dry gases in a duct (assumed to have the composition of air) by taking into account both the absolute pressure of the stream and the presence of moisture"[3]. An analysis by $\mathrm{Yu}$ [4] indicated that if moisture is neglected during sprinklered fire tests, chemical heat release rates can be over-estimated by $14 \%$.

The second variable in Eq. 2 that needs to be examined is the mole fraction of each species. Calculation of the chemical heat release rate from measured gas concentrations requires a correction for distortions in the measured signals. These distortions occur as a result of mixing of the combustion products in the volume of space above the movable ceiling. The analysis presented here is based on using a simple first order correction, Eq. 4 [5].

$X_{i, \text { corrected }}=f\left(X_{i, \text { measured }}\right)=X(t)_{i, \text { measured }}+\tau \frac{d X(t)_{i, \text { measured }}}{d t}$

In addition, accumulation of mass within the large volume of space above the movable ceiling needs to be taken into account and will be discussed later.

The time constant, $\tau$, in Eq. 4 is a function of the volume above the ceiling and the ventilation rate:

$\tau \propto C\left(\frac{V}{\dot{V}}\right)$

In the absence of experimentally determined values for the time constant, the calculations presented here are based on the initial assumption that $\tau=V / \dot{V}$. An additional correction is applied to adjust for mass accumulation above the moveable ceiling. If the value of the time constant is incorrect, then the predicted values will be either over- or underestimated. If the value of the time constant is too large, then the peak value will be overestimated with a corresponding negative compensation. If the value of the time constant is too small, then the peak chemical heat release rate will be underestimated and the time at which it returns to zero will not correspond to the experimental time at which the fire was extinguished. For all tests, the ventilation rate was $94.4 \mathrm{~m}^{3} / \mathrm{s}$. The ceiling height and time constant for each test are provided in Table 1.

The final variables in Eq. 1 are the net heats of complete combustion per unit mass of $\mathrm{CO}_{2}$ and $\mathrm{CO}$ generated. All values were taken directly from Tewarson [2]. For heptane, the exact values were selected, while for mineral oil, the average values for normal alkanes were used, and for the FM Global Standard Plastic Test Commodity, mixed fuel values were used. For each commodity, the values of $\Delta h_{c, \mathrm{CO}_{2}}$ and $\Delta h_{c, \mathrm{CO}}$ used in the calculations are listed in Table 1. 
Table 1. Test commodities and test variables.

\begin{tabular}{|l|c|c|c|c|}
\hline \multicolumn{1}{|c|}{ Commodity } & $\begin{array}{c}\Delta h_{c, C O_{2}} \\
\mathbf{( k J / k g )}\end{array}$ & $\begin{array}{c}\Delta h_{c, C O} \\
(\mathbf{k J} / \mathbf{k g})\end{array}$ & $\begin{array}{c}\text { Ceiling } \\
\text { Height } \\
(\mathbf{m})\end{array}$ & $\begin{array}{c}\tau \\
(\mathbf{s e c})\end{array}$ \\
\hline Mineral Oil & 14,600 & 12,900 & 18.3 & 34 \\
\hline Heptane & 14,500 & 12,800 & 12.2 & 69 \\
\hline Standard Plastic & 13,300 & 11,100 & 9.1 & 94 \\
\hline
\end{tabular}

To validate the correction methodology discussed above, two heptane pan fire tests were conducted, one under the movable ceiling and one under the 20 MW Calorimeter. The theoretical heat release rate for the heptane pool fire can be determined based on pool burning correlations found in the literature [6].

$\dot{Q}=\dot{m}^{\prime \prime} \Delta H_{c} \chi_{\text {chem }}\left(\frac{\pi D^{2}}{4}\right)$

Where the equivalent diameter for a $2.13 \mathrm{~m}$ by $2.13 \mathrm{~m}$ square pan fire is $2.41 \mathrm{~m}$, and values in the literature for $\dot{m} "$ range between $0.066 \frac{\mathrm{kg}}{\mathrm{m}^{2} \mathrm{~s}}$ and $0.101 \frac{\mathrm{kg}}{\mathrm{m}^{2} \mathrm{~s}}$ [6,7]. Using typical values for $\chi_{\text {chem }}=0.92$ and $\Delta H_{c}=44,600 \frac{\mathrm{kJ}}{\mathrm{kg}}$, the theoretical chemical heat release rate is between 12.4 and $18.9 \mathrm{MW}$.

As with most calorimeter data, only a simple time shift, accounting for the transport time, is required to correct the measured data. The chemical heat release rates for both tests are shown in Fig. 4. The ceiling data includes the calculated chemical heat release rates based on uncorrected data along with two different corrected curves. In addition, the theoretical values are also shown.

The calorimeter data are within $-12 \%$ and $25 \%$ of the theoretical values and agree in duration to the actual test duration, 270 seconds. Conversely, the uncorrected ceiling data yield a chemical heat release rate (implying a longer duration, lower intensity fire) that is inconsistent with visual observations. This appears to be the result of the accumulation and dilution of the combustion products in the space above the movable ceiling. If the overall system could be represented as a simple mixing problem, then the $1^{\text {st }}$ order correction, Eq. 4, mentioned previously, would adjust the data to agree with the calorimeter data. The predicted magnitude falls below the theoretical and calorimeter values and the test duration appears to be approximately 105 seconds longer than the actual test. 


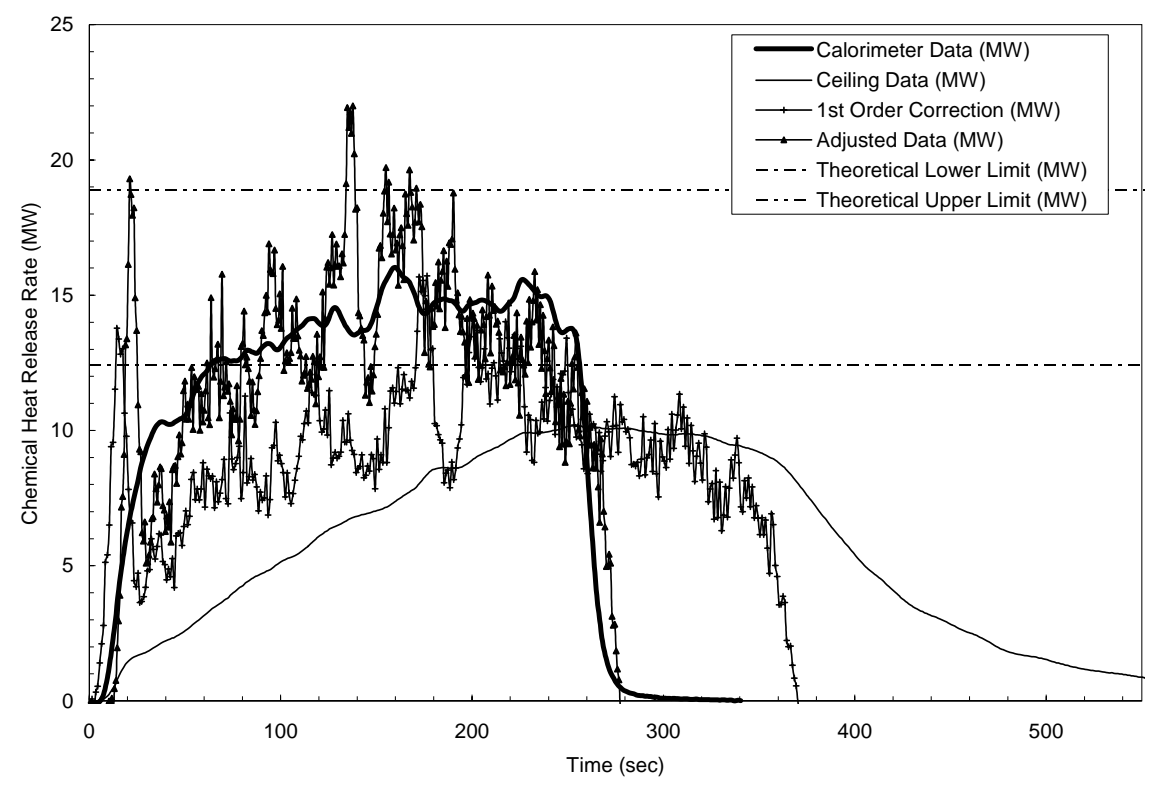

Fig. 4. Heptane pool fire chemical heat release rates.

A total of $0.115 \mathrm{~m}^{3}$ of heptane was consumed in each test; therefore, the total energy released was 3,210 MJ. Integrating the calculated chemical heat release rates, the total energy released is estimated to be 3,200 MJ and $3280 \mathrm{MJ}$ for the ceiling and calorimeter tests, respectively. The measured values are within $2.7 \%$ and $-2.2 \%$ of the theoretical value. Since integration of the heat release rate data eliminates any dependency on the time constant discussed previously, this is an indication that the physical measurements are correct. However, the first order correction for gas mixing within the plenum is not sufficient and an additional correction, accounting for accumulation of mass above the ceiling, is required.

Since the total energy is the same between the two tests, multiplication factors to adjust the time and chemical heat release rates can be determined. The correction factors were determined to be $\mathrm{x}_{\text {time }}=0.72$ and $\mathrm{x}_{\mathrm{CHRR}}=1 / \mathrm{x}_{\mathrm{time}}=1.4$. The corrected ceiling data and calorimeter data are now in good agreement, and both results agree with visually observed test durations of approximately 270 seconds.

The correction factors will not be constant for all test configurations and will be a function of the volume of space above the movable ceiling. To conserve total energy, the product of the two correction coefficients must be equal to 1.0. For other data examined, a linear relationship between the volume and each correction factor was assumed along with the condition that no correction, i.e., $\mathrm{x}_{\text {time }}=\mathrm{x}_{\mathrm{CHRR}}=1.0$, is required when the volume is zero.

\section{RESULTS AND DISCUSSION}

The methodology discussed above is applied to test data from two large-scale fire tests - a free-burn spray fire and a sprinklered rack storage fire. The calculated chemical heat release rate data are compared to theoretical values and to observed events. 


\section{Free-burn Spray Fire}

In conjunction with a larger test series, a free-burn mineral oil spray fire test was conducted under the movable ceiling set at $18.3 \mathrm{~m}(60 \mathrm{ft})$. The ideal heat release rate for a spray fire can be calculated using:

$\dot{Q}=\beta \rho \dot{V} \chi_{A} \Delta H_{T}$

Where $\beta$ is the evaporation fraction and a function of the droplet diameter. Using values of 0.85 for $\beta, 0.95$ for $\chi_{\mathrm{A}}, 834 \mathrm{~kg} / \mathrm{m}^{3}$ for $\rho$, and 44,400 for $\Delta H_{T}$ along with the measured flow rate, the average ideal heat release rate is estimated to be $37.2 \mathrm{MW}$. The calculated and theoretical chemical heat release rates, as a function of time for the free-burn spray fire, are shown in Fig. 5. The calculated chemical heat release rate was first determined by using the first order correction with a time constant of 35 seconds. Then, the time axis was adjusted by a factor of 0.93 and a corresponding adjustment to the chemical heat release rate $(1 / 0.93=1.08)$. During the steady-state period $(60$ seconds $<\mathrm{t}<$ 100 seconds) the average calculated chemical heat release rate was $38.7 \mathrm{MW}$, a difference of $4.0 \%$ compared to the theoretical value.

While the test duration does not appear to be in agreement, approximately $(1-\beta) * 100=$ $15 \%$ droplet fallout resulted in a pool fire that persisted after termination of the spray fire. This would also contribute to the higher calculated chemical heat release rate, compared to the theoretical value.

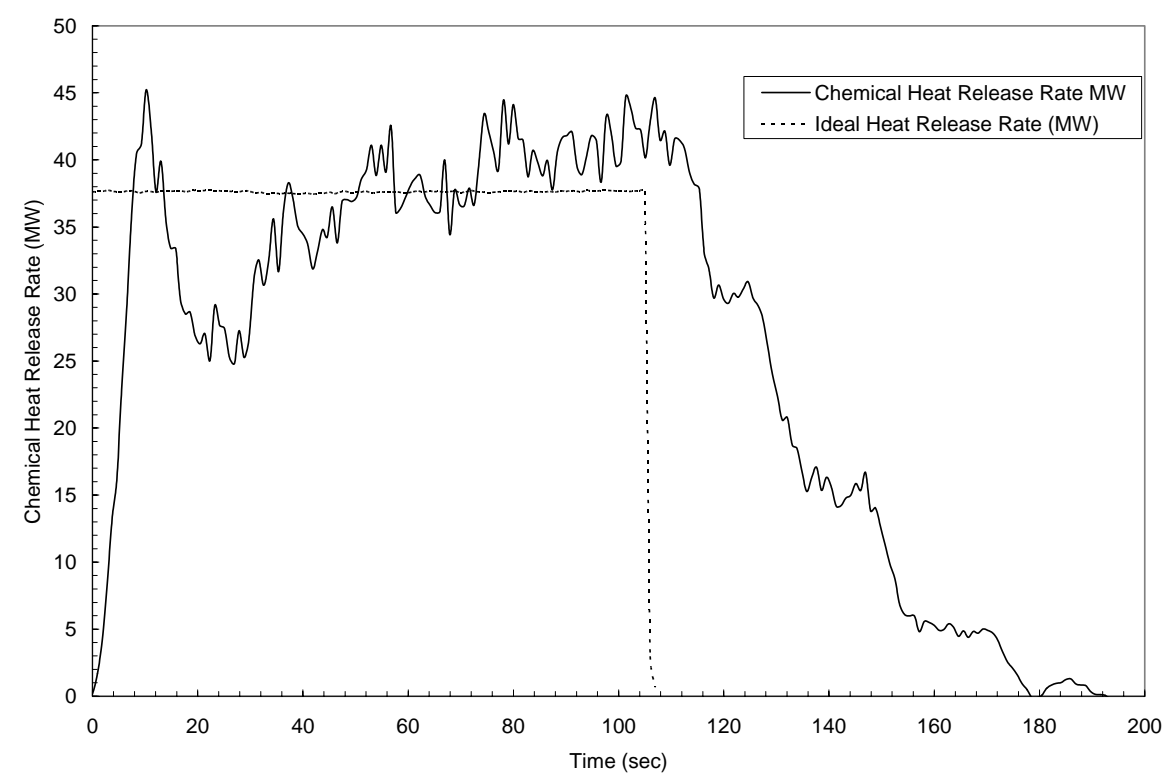

Fig. 5. Comparison between theoretical and calculated chemical heat release rates for mineral oil spray fire. 


\section{Rack Storage Fire}

A rack storage fire test was conducted using the FM Global "Standard Plastic" test commodity. The commodity consists of 125 empty, $473 \mathrm{ml}$ unexpanded polystyrene cups that are individually compartmentalized within a corrugated paper carton. Eight cartons, forming $1.21 \mathrm{~m}^{3}$, are stacked on a wood pallet. Pallet loads were arranged on open-frame steel racking. The two-tier, $2.7 \mathrm{~m}$ high loaded rack was located under the moveable

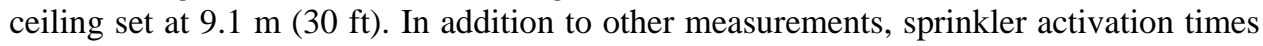
were recorded during the test. Ten sprinklers operated; the first sprinkler operated at 50 seconds and the second at 102 seconds.

Two calculated chemical heat release rates, one based on Eq. 1 and the second, including the time and magnitude adjustment, are shown in Fig. 6. The time and magnitude correction factors were 0.61 and $1 / 0.61=1.64$, respectively. Only 150 seconds of data, starting at ignition, are presented.

Examining the data in Fig. 6, it is observed that the first reduction in the adjusted chemical heat release rate corresponds to the activation of the first sprinkler, while the chemical heat release rate, based on the $1^{\text {st }}$ order correction, implies that the first sprinkler operated at approximately 80 seconds, 30 seconds after the actual operation. This is further validation that the $1^{\text {st }}$ order correction is not sufficient. It should be noted that upon sprinkler activation, the adjusted chemical heat release data no longer appear to properly correspond to visually observed and electronically recorded events during the test. The subsequent reductions in chemical heat release rate appear at 65 seconds, 75 seconds and 85 seconds, alluding to potential sprinkler operation. However, the second sprinkler was not observed to activate until 102 seconds.

The data indicate that a single adjustment factor may not be sufficient to account for changing fluid dynamics within the space upon sprinkler activation.

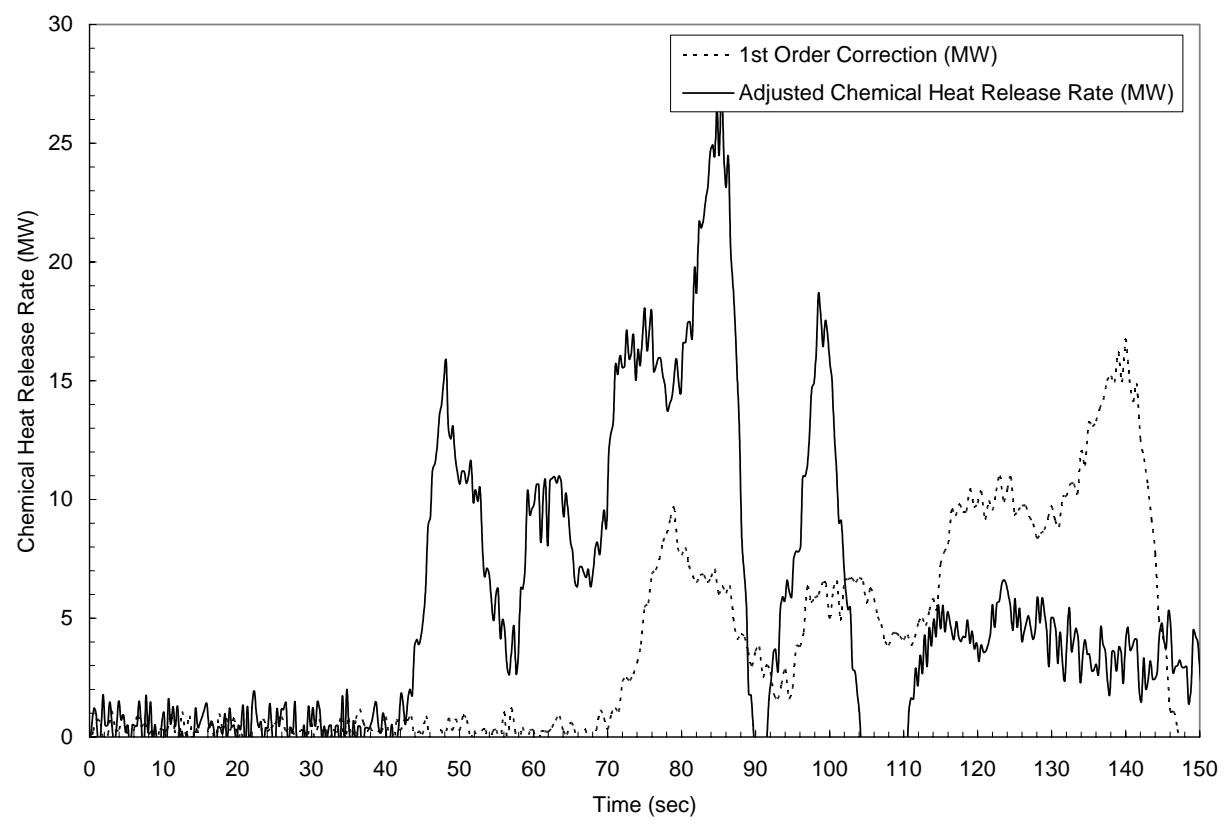

Fig. 6. Chemical Heat Release Rates for rack storage test. 


\section{CONCLUSIONS}

The theory and calculations required to calculate chemical heat release rates for largescale fire tests conducted in the FM Global Large Burn Laboratory are presented and discussed. Corrections to the measured species data are required to account for accumulation and mixing within the large volume of space above the movable ceiling. Data from a limited number of tests indicate that a simple $1^{\text {st }}$ order correction for mixing within the space is inadequate. A time and magnitude adjustment based on the conservation of total energy is proposed. The methodology is applied to a free-burn spray fire and a sprinklered rack storage fire, and then compared to theoretical heat release rates and observed test events. Good agreement is seen for times prior to sprinkler operation; however, upon sprinkler operation, the time adjustment indicates a shorter test duration than that observed. Further investigation is required to assess whether a single or multiple correction factors will need to be applied during sprinklered fire tests. A detailed investigation, in which, key variables will be systematically varied to determine their impact on the gas transport and mixing times along with the correction factors is scheduled for the near future.

\section{AKNOWLEDGEMENTS}

The authors would like to thank Franco Tamanini, John DeRis, and Prateep Chatterjee for their valuable input and discussions on these topics.

\section{REFERENCES}

[1] Heskestad, G., "A Fire Products Collector for Calorimetry into the MW Range,” Factory Mutual Research Corporation, Norwood, MA, 1981.

[2] Tewarson, A., "Generation of Heat and Chemical Compounds in Fires," The SFPE Handbook of Fire Protection Engineering ( $3^{\text {rd }}$ ed), DiNenno, P.J. (ed.), National Fire Protection Association, Quincy, MA 02269, 2002, pp. 3/82-3/161.

[3] Tamanini, F., personal communication.

[4] Yu, H.Z., personal communication.

[5] Croce, P., "A Method for Improved Measurement of Gas Concentration Histories in Rapidly Developing Fires," Combustion Science and Technology, 14, pp. 221-228, (1976).

[6] Zalosh, R., Industrial Fire Protection Engineering, John Wiley and Sons, Chichester, 2003, p. 216.

[7] Tewarson, A. and Newman, J., "Scale Effects on Fire Properties of Materials," Fire Safety Science - Proceedings of the First International Symposium, International Association for Fire Safety Science, 1986, pp. 451-462. 